\title{
PERMASALAHAN PEMBINAAN WARGA GEREJA DI KEWARI
}

\author{
Ruat Diana \\ Sekolah Tinggi Teologi Simpson \\ Jl. Agung No. 66, Krajan, Kel. Susukan, Kec. Ungaran Timur, Kab. Semarang, Jawa Tengah \\ Email: rdianadarmawan@gmail.com
}

\begin{abstract}
Ruat Diana, This article discusses the issue of church community development in Kewari. The main focus of this article is the difficulty of fostering church members to the Kewari community. Through this research, the authors describe the factors behind the difficulty of fostering church members in Kewari. These factors are seen from social and historical aspects. The author assesses the importance of exposing it as a reflection in carrying out church community development. The pattern of community life, language differences and the slow adjustment of language, the level of community education, and the beliefs of the community became a factor of difficulty of building church people in Kewari
\end{abstract}

Keywords: Social, Church, Kewari.

ABSTRAK: Ruat Diana, Permasalahan Pembinaan Warga Gereja di Kewari. Artikel ini membahas tentang permasalahan pembinaan warga gereja di Kewari. Fokus utama dari artikel ini adalah faktor kesulitan pembinaan warga gereja kepada masyarakat Kewari. Melalui penelitian ini, penulis menggambarkan faktor-faktor yang melatarbelakangi kesulitan pembinaan warga gereja di Kewari. Faktor-faktor tersebut dilihat dari aspek sosial dan sejarah. Penulis menilai pentingnya memaparkan hal tersebut sebagai sebuah refleksi dalam melaksanakan pembinaan warga gereja. Pola hidup masyarakat, perbedaan bahasa dan lambatnya penyesuaian bahasa, tingkat pendidikan masyarakat, dan keyakinan masyarakat menjadi faktor kesulitan pembinaan warga gereja di Kewari.

Kata kunci: Sosial, Gereja, Kewari.

\section{PENDAHULUAN}

Pemberitaan Injil merupakan amanat agung Yesus Kristus (Mat. 28:19-20). Secara umum amanat agung Yesus Kristus dalam Matius 28:19-20, dipahami sebagai tugas bagi semua orang Kristen untuk pergi memberitakan kabar baik (Wijaya \& Darmawan, 2016, p. 52). Ayat tersebut juga berbicara tentang "ajarlah" warga gereja agar mereka dapat melakukan apa yang Kristus ajarkan. Oleh sebab itu, Matius 28:19-20 juga menekankan pada pembinaan warga gereja. Dengan dasar alkitab itu pemberitaan Injil dilakukan agar orang-orang mengenal Kristus Yesus kemudian dibina agar mengalami pertumbuhan. Bagi orang Kristen Injili, keyakinan bahwa Kristus Juruselamat dan tugas amanat agung tersebut harus terus dilaksanakan kepada dunia ini agar semakin banyak orang yang percaya kepada Kristus dan beroleh hidup kekal (Objantoro, 2017, p. 138). Kemudian, Susanto (2016, p. 19) dalam laporan penelitiannya mengungkapkan bahwa tugas gereja adalah membantu setiap orang mengenal Kristus kemudian berakar dan dibangun di atas Dia, teguh dalam iman serta hati yang melimpah dalam syukur (Kol. 2:7). Agar warga gereja dapat mengalami pertumbuhan, maka pembinaan warga gereja sangatlah penting. Dari itu, tampak jelas bahwa pembinaan warga gereja merupakan hal penting bagi perkembangan gereja. Dengan dilaksanakannya pembinaan warga gereja, anggota jemaat dapat mengalami pertumbuhan rohani, kemudian berdampak pada pertumbuhan gereja secara menyeluruh.

Sebagaimana telah dikemukakan di atas, jelas bahwa pertumbuhan gereja dapat terjadi ketika pemberitaan Injil dan pembinaan warga gereja dapat berjalan dengan baik. Demikian juga dalam pengembangan pelayanan Gereja Kemah Injil Indonesia (GKII) di Daerah Barito Tengah, Kalimantan Tengah. Injil telah masuk di Dusun (Pen.: Kampung) Kewari, salah satu daerah pelayanan GKII Daerah Barito Tengah. Masuknya Injil di Kewari berkaitan 
erat dengan program pemberitaan Injil oleh Kingmi (Sekarang GKII) Kaltim. Pendeta-pendeta Kingmi yang memberitakan Injil di Kewari adalah Pdt. Ruben C. Liem, Pdt. Mutang Sia, Pdt. Piet Kanter, Pdt. Zasterman, Pdt. Yas.

Injil masuk ke desa Kewari pada tahun 1989, terkait dengan adanya seorang pendeta GKII yang bernama Pdt. Mutang Sia, diutus ke Benangin dan ditempatkan di desa Benangin I, pendeta itu sangat pandai untuk membangun hubungan dengan masyarakat setempat. Awal mulanya pendeta itu berkenalan dengan keluarga Nika Nor dan ibu Kartina. Bapak Nika Nor dan ibu Kartina memperkenalan keluarga Bunsu dengan Pdt. Mutang yang melayani di Benangin I. Pendeta tersebut membantu keluarga Bunsu untuk mengetam (memanen) padi, sehingga terjadi perkenalan yang kemudian berlanjut menjadi pembinaan terhadap keluarga Bunsu. Pembinaan dilakukan setiap hari Jumat dengan mengadakan persekutuan doa. Pendeta tersebut datang ke Kewari dengan berjalan kaki menempuh perjalanan $7 \mathrm{~km}$, kemudian pada hari Sabtu kembali ke Benangin I. Persekutuan yang dibuka di Kewari berdampak pada bergabungnya keluarga Bapak Tika (Alm.), keluarga Bapak Hok, dan Ibu Esoh. Sampai tahun 1990 kegiatan doa dan pedalaman Alkitab berjalan dengan baik dan banyak warga yang lain yang tertarik, sehingga Bapak Bunsu, sebagai ketua persekutuan Doa menyampaikan kepada warga bahwa bagi yang mau bergabung dipersilahkan, yang penting semua keluarga setuju dan pihak dari persekutuan ini tidak ada memaksa. Tetapi karena adanya masalah yang disebabkan oleh pihak lain, Pdt. Mutang Sia kemudian dimutasi karena alasan keamanan. Paska mutasinya Pdt. Mutang Sia, tiga keluarga Kristen baru di Kewari ditinggal begitu saja tanpa ada pembinaan lebih lanjut. Karena kondisi orang Kristen di Kewari kurang dilayani oleh pendeta, pihak dari Gereja Kalimantan Evangelis (GKE) kemudian setiap satu tahun sekali tepatnya saat Natal mengadakan kunjungan ke Kewari, tetapi seiring berjalannya waktu dan beberapa persoalan pihak GKE juga tidak melanjutkan pelayanan mereka.
Lalu pada tahun 1998 ada dua mahasiswa dari Tunas Kalimantan (Tukal), Kalimantan Selatan melayani di Kewari, tetapi tidak ada juga orangorang mau percaya Injil dengan alasan agama Kristen adalah agama baru. Tokoh-tokoh masyarakat dan orang tua memberi pandangan kepada anak-anak muda agar jangan mengikuti agama yang baru, sebab agama baru itu menyesatkan. Kemudian pada tahun 2004 ada lagi satu hamba Tuhan dari Gereja Bethel Indonesia (GBI) yang mencoba untuk melayani di Kewari. Pendeta dari gereja tersebut masuk ke Kewari dengan berdagang sembako sebagai alat komunikasi kepada masyarakat dan untuk membangun hubungan yang baik dengan tokoh-tokoh Kaharingan dan tokoh perdukunan. GBI kemudian memperoleh hibah tanah yang lokasinya berdekatan dengan kuburan. Secara bertahap GBI membangun tempat Ibadah di lokasi tersebut. Pada tahun 2012, pendeta yang melayani di GBI Kewari meninggal dan pelayanannya dilanjutkan oleh istrinya sampai sekarang. Hanya secara kuantitas pelayanan di Kewari tidak mengalami perkembangan yang baik.

Kondisi pelayanan di Kewari hingga tahun 2012 kurang berkembang, hal itu terbukti dari minimnya jumlah orang Kristen baru dan yang hidupnya dewasa dalam kekristenan. Berdasarkan informasi dari beberapa sumber diperoleh informasi bahwa ada beberapa faktor penyebab pembinaan warga gereja di Kewari tidak dapat berjalan dengan baik. Melihat hal itu maka penulis memandang perlu diteliti apa yang menjadi faktor penyebab pembinaan warga gereja di Kewari tidak berjalan dengan baik. Dengan meneliti secara historis dan mencermati aspek sosial pelaksanaan pembinaan warga gereja di Kewari, maka dapat diuraikan faktor permasalahan yang terjadi di tempat tersebut. Dalam konteks penelitian ini penulis lebih menyoroti Kewari secara umum tidak pada denominasi gereja yang saat ini ada di tempat tersebut. Rumusan masalah dari penelitian ini adalah apa saja kesulitan pelaksanaan pembinaan warga gereja di Kewari? Kemudian tujuan dari penelitian ini adalah untuk memaparkan secara deskriptif kesulitan pembinaan warga gereja di Ke- 
wari. Hasil penelitian ini diharapkan dapat memberi manfaat sebagai refleksi dalam melaksanakan pembinaan warga gereja.

\section{METODE}

Jenis penelitian ini adalah penelitian kualitatif. Karena penelitian kualitatif merupakan penelitian yang melibatkan data-data kualitatif, maka proses pengumpulan data dilakukan dengan melakukan wawancara kepada beberapa informan. Penelitian di dilakukan di Kewari, Desa Benangin I, Kecamatan Teweh Timur, Kabupaten Barito Utara. Data-data dalam penelitian ini, penulis peroleh dari beberapa masyarakat berupa data awal seperti masuknya Injil di Kewari. Proses pengumpulan data awal dilakukan pada tahun 2010, kemudian ditindaklanjuti dengan pengumpulan data lain dari sumber-sumber tertentu hingga tahun 2017. Data-data awal penulis kumpulkan dengan wawancara kepada beberapa informan dan observasi langsung, kemudian ditindaklanjuti dengan pengumpulan data pendukung. Secara umum penulis pernah tinggal di Kewari sehingga pengamatan selama tinggal di Kewari kemudian didalami dengan mengumpulkan data dari beberapa informan. Informasi dari para informan membantu penulis menguraikan faktor kesulitan pembinaan warga gereja di Kewari, Kalimantan Tengah. Data yang diperoleh kemudian dianalisa dengan memilah data dan dikelompokkan, kemudian diuraikan secara deskriptif.

\section{HASIL DAN PEMBAHASAN}

\section{Gambaran Objek Penelitian}

Kewari berada di Wilayah Pemerintahan Kecamatan Teweh Timur, Kabupaten Barito Utara, Propinsi Kalimantan Tengah. Ibu kota Kecamatan Teweh Timur adalah Benangin I (BPS, 2011b, p. 1). Masyarakat Kewari adalah masyarakat yang mayoritas memegang keyakinan Kaharingan dan beberapa orang menganut agama Kristen. Suku mayoritas di kampung tersebut adalah dari suku Dayak Taboyan (Taboyan). Secara umum pekerjaan penduduk Kewari adalah petani ladang serta mengusahakan rotan, sama seperti penduduk Teweh Timur pada umumnya (Weinstock, 1996, p. 60). Ada beberapa upacara yang dilakukan oleh suku Dayak Taboyan seperti upacara tiwah atau bagi suku Dayak Taboyan disebut dengan gomeh wara (Hanifi, 2016, p. 86). Selain upacara tiwah, masyarakat Kewari melakukan upacara Balian. Balian merupakan upacara perdukunan yang biasa dilakukan oleh orang Kaharingan di Kalimantan Tengah dan Kalimantan Selatan. Upacara ini juga biasa dilakukan di beberapa desa di Kutai Barat, Kalimantan Timur. Upacara Balian menjadi media pengobatan bagi keluarga yang sakit bagi masyarakat Kewari.

\section{Hasil dan Pembahasan}

Dari data yang dikumpulkan melalui sumbersumber yang terkait dengan pembinaan warga gereja di Kewari maka ada berapa faktor kesulitan pembinaan warga gereja di Kewari pasca menjadi Kristen.

\section{Transisi Budaya}

Beberapa tradisi gereja tampaknya tidak terlalu diminati oleh masyarakat Kewari seperti jika ibadah harus berrnyanyi dan tepuk tangan. Nyanyian dikala duka tidaklah disenangi oleh masyarakat Kewari, mereka merasa bahwa lebih baik hidup di Kaharingan sebab ketika mati diratap dan ditangisi sepuasnya. Hal tersebut tentunya berkaitan dengan pola pikir masyarakat yang telah terbentuk melalui pendidikan masyarakat yang berjalan turun-temurun.

Kegitan selanjutnya yang tidak diminati adalah pemberian persembahan. Alasannya adalah karena ada persepsi bahwa pendeta yang melayani "makan" uang yang diberikan melalui persembahan. Pendeta yang melayani di Kewari dengan tanpa pendapatan yang jelas, menambah keyakinan bahwa kehidupan pendeta tersebut bergantung dengan sumbangan jemaat. Oleh sebab itu, jika ada yang telah menjadi Kristen jarang sekali mereka mau menyerahkan anaknya menjadi hamba Tuhan, karena pandangan mereka hamba Tuhan terlalu miskin.

Dari informasi yang penulis peroleh ketetahui bahwa beberapa pendeta yang menyampaikan 
Injil di Kewari, kurang memahami hal di atas sehingga komunikasi Injil tidak dilakukan dengan pendekatan yang baik tetapi secara frontal. Dalam hal ini, penulis melihat adanya upaya untuk segera mengarahkan masyarakat pada perubahan cara ibadah tanpa terlebih dahulu melakukan pendekatan dan memberikan pemahaman.

Secara sosiologi, sesuatu yang baru dianggap sebagai hal yang aneh bagi masyarakat karena berbeda dengan kebudayaannya, kemudian pada beberapa kelompok masyarakat ada kebanggaan pada budaya sendiri dibandingkan dengan budaya baru (Ihromi, 1990, p. 14). Bila masyarakat perkotaan jauh lebih mudah untuk menerima perubahan atau mengalami transisi dari budaya lama ke budaya baru, berbeda dengan masyarakat desa yang cenderung lebih memilih bertahan pada budayanya sendiri (Johnson, 1986, p. 23). Jika demikian, tidak heran bila masyarakat Kewari lebih memilih bertahan dengan budayanya dan sulit menerima hal-hal yang berkaitan dengan kekristenan. Dalam hal ini pada dasarnya tidak ada yang salah pada tradisi gereja, hanya masyarakat yang cenderung kurang siap menerimanya, sehingga komunikasi Injil dan pembinaan warga gereja dapat mengalami hambatan.

\section{Pola Hidup Masyarakat}

Masyarakat Kewari lebih banyak tinggal di ladang-ladang mereka, walaupun mereka memiliki rumah di Kewari. Jarak dari satu ladang ke ladang yang lain cukup jauh, demikian pula jarak dari kampung juga sangat jauh. Kondisi penduduk pada rentang tahun 1980 hingga 1995 masih berpindah-pindah dari satu ladang ke ladang yang lain. Kemudian untuk memenuhi kebutuhan hidup, penduduk Kewari berburu binatang liar di hutan-hutan. Kondisi seperti ini menjadi tantangan tersendiri untuk melakukan pembinaan warga gereja. Beberapa pendeta yang melakukan kunjungan ke Kewari menjadi kesulitan menemui masyarakat karena sebagian besar akan tinggal di ladang-ladang mereka. Dengan kondisi seperti diungkapkan di atas dan ditambah dengan beberapa pendeta yang datang dari Kalimantan Timur tidak tinggal menetap di Kewari dan orang-orang Kewari tidak tinggal menetap di kampung menyebabkan timbulnya kesulitan pembinaan pasca menjadi Kristen. Hal tersebut kemudian berdampak pada pelayanan pembinaan warga gereja oleh pendeta yang melayani di Kewari tidak berjalan dengan baik. Sebagai contoh pendeta yang melayani di Kewari setelah adanya masyarakat yang menjadi Kristen, pelayanaan pembinaan masih berupa pelayanan perkunjungan. Sementara dengan masyarakat yang tinggal di ladang-ladang menyebabkan pendeta menjadi semakin sulit melakukan kunjungan, oleh sebab itu program pembinaan tidak dapat berjalan dengan baik. Hal tersebut kemudian berdampak pada kurangnya intensitas perkunjungan atau pelayanan pastoral sebagai bagian dari pembinaan warga gereja. Baier (2014, p. 167) dalam jurnal laporan penelitiannya menjelaskan bahwa kunjungan pendeta yang sifatnya temporal ke daerah pelayanan di pedalaman menjadi faktor orang Kristen kembali ke agama suku. Penelitian Baier di Kalimantan Tengah yang lebih menyoroti pelayanan di GKE pada abad 19 yang bentuknya pelayanan perkunjungan dari gereja induk ke pos pelayanannya, tampaknya terjadi juga dalam pelayanan GKII di kawasan Teweh Timur khususnya Kewari pada rentang tahun 1989-1990.

Selain itu, kebiasaan hidup berjudi menjadi tantangan tersendiri bagi pendeta yang melayani di Kewari. Kartina (2015) menjelaskan bahwa ada kecenderungan penduduk Kewari lebih tertarik untuk berjudi dibandingkan mengikuti hal-hal yang terkait dengan kekristenan. Di Kewari, perjudian dilakukan baik oleh laki-laki dewasa maupun ibu-ibu rumah tangga, sehingga anak-anak juga melihat teladan seperti itu dan akhirnya lambatlaun mengikuti hal itu. Mengubah pola hidup masyarakat tentunya tidak dapat dilaksanakan dengan mudah. Beberapa masyarakat yang tidak berladang cenderung akan memilih untuk berjudi sehingga ketika ada pelayanan pendeta, mereka tidak tertarik dengan pelayanan pendeta dan fokus pada pilihan untuk berjudi. Dari dua permalasahan yang berkaitan dengan pola hidup masya- 
rakat, masalah pertama di atas menjadi masalah yang lebih dominan dibandingkan dengan masalah kedua.

Pola hidup masyarakat sangat terkait dengan pola pikir mereka. Pola pikir tentunya terkait juga dengan tingkat pendidikan masyarakat. Tingkat pendidikan yang rendah menyebabkan pola pikir warga gereja maupun masyarakat Kewari secara umum masih harus dibangun dengan baik. Hanya, melakukan hal ini ternyata tidak mudah. Mengacu pada uraian B.S. Sidjabat (2014), Riniwati (2016, pp. 1-2) menuliskan bahwa salah satu aspek penting yang berkaitan dengan kedewasaan adalah aspek kedewasaan secara psikologis, dimana masyarakat menjadi mapan dalam cara berpikir, kemudian dalam mengelola emosi, maupun dalam menyatakan sikap berkaitan dengan pengambilan keputusan. Informasi dari beberapa informan diketahui bahwa pernikahan dini menjadi salah satu penyebab putus sekolah di Kewari. Secara umum data dari BPS (2011a, p. 18) menunjukkan bahwa tingkat pendidikan masyarakat Benangin I pada tahun 2011 adalah SD sebanyak 168, SMP sebanyak 196, dan SMA sebanyak 142. Di Desa Benangin I terdapat 3 SD yang salah satunya berada di Kewari. Penulis menilai faktor pendidikan berkontribusi pada sulitnya mengubah pola pikir masyarakat terutama untuk dapat menerima hal-hal yang baru, khususnya yang terkait dengan budaya.

\section{Bahasa}

Dalam bahasa Taboyan tidak ada istilah yang dapat digunakan untuk menjelaskan tentang percaya kepada Yesus. Dalam konteks bahasa Tawoyan kata "Persaya" (Ind.: Percaya) sulit untuk digunakan menjelaskan tentang percaya pada Yesus. Kata "Persaya" dapat digunakan hanya sebatas komunikasi pada masalah sosial. Orang Taboyan akan lebih mudah memahami ajakan percaya pada Yesus jika menggunakan kata "Nyang" yang artinya ikut. Beberapa pendeta yang memberitakan Injil dan melakukan pembinaan warga gereja di Kewari dari tahun 1983-1990, seperti Pdt. Ruben C. Liem, Pdt. Mutang Sia, Pdt. Piet Kanter, Pdt. Zasterman, Pdt. Yas, sebagaian besar belum memahami tentang peng- gunaan bahasa tersebut. Pendeta-pendeta tersebut berasal dari suku Dayak Lundayeh dan Suku Dayak Kenyah dari Kalimantan Timur, hanya bisa memberitakan Injil dan mengajar dengan menggunakan bahasa Indonesia. Sementara masyarakat Kewari belum banyak menguasai Bahasa Indonesia, komunikasi mereka pada tahun tersebut menggunakan bahasa Taboyan. Kemudian pada tahun 2002-2013 pemberitaan Injil dan pembinaan warga gereja yang dilakukan oleh Pdt. Imo mengalami hambatan bahasa. Pdt. Imo yang berasal dari suku Dusun Kalahien yang memiliki latar belakang bahasa yang berbeda tampaknya kurang memahami konteks bahasa. Hal tersebut menjadi salah satu alasan sulitnya mengomunikasikan Injil maupun mengajarkan firman Tuhan kepada masyarakat di Kewari.

Permasalahan lain terkait dengan bahasa adalah masyarakat Kewari dalam berkomunikasi cenderung menggunakan bahasa kiasan. Bahasa-bahasa kiasan yang digunakan oleh masyarakat Kewari cenderung sulit dipahami oleh orang yang tidak memahami bahasa Taboyan. Sementara pendeta yang diutus ke Kewari jarang bisa memahami bahasa Taboyan. Masyarakat Kewari menganggap jika orang yang ditugaskan di Kewari dapat menguasai bahasa Taboyan maka mereka akan disenangi dan dianggap tidak sombong.

Dengan latar belakang pendidikan masyarakat yang rendah dan beberapa orang tua mengalami kesulitan untuk memahami bahasa Indonesia, menyebabkan adanya kesulitan dalam mengajarkan firman Tuhan. Sementara bagi generasi muda yang menempuh pendidikan dapat memahami bahasa Indonesia, hanya tidak semua orang muda di Kewari dapat menggunakan dan memahami bahasa Indonesia dengan baik.

Bahasa sangatlah penting untuk berkomunikasi, sebab "bahasa, kata, gesture, tanda, merupakan hal-halyang digunakan manusia dalam mendefinisikan sesuatu atau menyampaikan sesuatu ke orang lain." (Watie, 2011, p. 70). Jika ada kesenjangan bahasa maka komunikasi tidak akan berjalan efektif. Astuti (2014, p. 309) mengungkapkan bahwa perca- 
kapan dapat dikatakan komunikatif apabila semua pihak baik komunikator maupun komunikan mengerti bahasa yang digunakan dalam penyampaian pesan. Kemudian Febriyanti (2014, p. 454) mengungkapkan tidak dapat dipungkiri jika ada perbedaan bahasa, maka tidak mungkin terjadi komunikasi antarbudaya yang efektif. Semakin besar perbedaan budaya maka akan terjadi perbedaan komunikasi baik dalam bahasa maupun dalam isyarat non verbal. Dari hal itu, penulis menilai bahwa perbedaan budaya dan bahasa menjadi penghambat komunikasi antara pendeta sebagai komunikator dengan dengan masyarakat atau warga gereja sebagai penerima pesan.

Untuk mengatasi masalah tersebut, upaya penerjemahan Alkitab ke dalam bahasa Taboyan telah dilaksanakan dalam kurun 15 tahun terakhir. Hanya sampai tahun 2017, proses penerjemahan Alkitab ke dalam bahasa Taboyan sebagai bahasa yang digunakan oleh masyarakat Kewari belum selesai. Informasi dari On (2017) menunjukkan bahwa proses penerjemahan Alkitab ke dalam bahasa Taboyan bagi masyarakat di Teweh Timur dan Gunung Purei belum selesai karena ada beberapa faktor. Hal ini tentunya terkait dengan pelayanan di Kewari sebagai salah satu bagian dari Kecamatan Teweh Timur.

\section{Keyakinan Masyarakat}

Masyarakat Kewari yang sebagaian besar memengang keyakinan Kaharingan sulit untuk menerima perubahan keyakinan. Keyakinan pada Kaharingan yang mengakar dalam kehidupan masyarakat di Kewari menjadi tantang bagi penginjil yang masuk ke kampung tersebut. Keyakinan yang kuat pada Kaharingan tampak dalam kebiasaan hidup mereka. Bunsu (2010) mengungkapkan bahwa masyarakat Kewari biasa melaksanakan upacara Balian ketika ada orang yang sakit. Masyarakat Kewari tidak hanya mengikuti upacara Balian yang dilaksanakan di Kewari, tetapi upacara yang dilaksanakan di tempat lain juga. Mahin (2009, p. 59) menjelaskan jika upacara Balian biasanya dipimpin oleh 5, 7, atau 9 orang imam (basir) dan dipimpin oleh seorang Basir Upu (imam utama). Kemudian Putri
(2017, p. 627) dalam jurnalnya mengungkapkan bahwa Balian merupakan pengobatan yang dilalui dengan adanya ritual-ritual kepada para roh untuk kesembuhan pasien yang mengikuti ritual Balian. Mereka biasanya mengikuti ritual Balian karena keyakinan mereka bahwa pengobatan Balian dapat menyembuhkan penyakit mereka. Informasi yang diperoleh dari beberapa informan diketahui bahwa beberapa masyarakat Kewari ada yang terlibat sebagai basir ketika upacara Balian dilaksanakan. Masyarakat Kewari lebih tertarik pada basir karena dengan tindakan yang dilakukan oleh basir, mereka melihat ada kesembuhan yang langsung terjadi. Sementara jika didoakan oleh pendeta, mereka merasa lebih sulit karena selain didoakan mereka disarankan untuk pergi ke dokter dan minum obat, itu dirasa tidak terlalu cepat untuk penyembuhan. Sidjabat (2014, p. 195) menjelaskan bahwa orang Indonesia cenderung tertarik pada hal-hal yang bersifat supranatural dibandingkan dengan yang bersifat rasional. Demikian halnya dengan masyarakat Kewari yang cenderung tertarik pada hal-hal yang bersifat supranatural dan merupakan pengalaman konkrit dibandingkan pengajaran yang menekankan aspek kognitif dan rasional.

Permasalahan lain berkaitan dengan pembinaan warga gereja adalah adanya sinkritisme dimana masyarakat Kewari mencapurkan hal-hal yang berkaitan dengan kekristenen dan ritual Kaharingan. Hal itu dilatarbelakangi adanya ketakutan jika satu waktu roh-roh nenek moyang yang mereka yakini akan datang menuntut mereka. Pada saaat ada kematian, jika anak yang meninggal telah menjadi Kristen maka akan dibuat dua ritual yaitu upacara Kristen dan ritual Kaharingan yaitu ritual gomek. Kemudian jika anak mereka sakit, walau sudah dibaptis mereka tetap akan di Belian dengan tujuan untuk mencari kesembuhan.

Terkait dengan perkunjungan pendeta yang tidak berjalan rutin, juga menyebabkan adanya orang-orang yang sudah menjadi Kristen dan membuang semua jimat-jimat serta yang berkaitan dengan ilmu hitam, akan kembali kepada kepercayaan 
lama ketika perkunjungan pendeta tidak berjalan dengan rutin terlebih jika pendeta tersebut sudah di mutasi atau masa praktiknya selesai dan tidak ada yang melanjutkan untuk membina.

Dari uraian di atas, jelas bahwa masyarakat Kewari memiliki rasa bangga pada keyakinan yang diturunkan oleh nenek moyang mereka. Masih terkait dengan kecenderungan percaya pada hal-hal yang bersifat supranatural, masyarakat Kewari tertarik dengan hal-hal yang berkaitan dengan roh-roh yang menyerupai buaya maupun harimau. Oleh sebab itu mereka cenderung bergantung pada roh-roh yang dapat dipanggil untuk menyembuhkan dan tidak pakai biaya yang banyak, serta hanya membuat sajen saja. Pada dasarnya keyakinan masyarakat pada hal-hal yang bersifat supranatural, sulit untuk diubah sebab pengalaman-pengalaman supranatural tersebut cenderung dipandang sebagai hal yang utama dan telah membentuk pola pikir seseorang. Sibjabat (2014, pp. 195-196) dalam bukunya menjelaskan bahwa pengalaman supranatural orang Indonesia pada umumnya lebih menekankan pada pengalaman emosional, intuisi, dan melihat bukti nyata. Hal tersebut dapat menjadi tantangan tersendiri dalam melaksanakan pembinaan warga gereja, sebab kecenderungan cara berpikir masyarakat Kewari tanpa dibarengi dengan pengalaman konkrit dapat menyebabkan sulitnya orang Kewari percaya pada firman $\mathrm{Tu}-$ han. Alkitab cederung dilihat sebagai sebuah harapan, tetapi pengalaman supranatural dan cerita nenek moyang dilihat sebagai sebuah pengalaman nyata.

\section{DAFTAR RUJUKAN}

Astuti, P. 2014. Komunikasi Sebagai Sarana Akulturasi Antara Kaum Urban Dengan Masyarakat Lokal Di Pasar Segiri Samarinda. eJournal Ilmu Komunikasi, 2 (1): 305-320.

Baier, G. M. 2014. Agama Hindu Kaharingan Sebagai Nativisme Sesudah Pengaruh Kristen Menjadi Peristiwa Yang Tak Ada Tandingannya. Jurnal Simpson: Jurnal Teologi dan Pendidikan Agama Kristen, 1 (2): 165-178.

\section{KESIMPULAN}

Dari hasil penelitian, penulis menemukan beberapa faktor yang menjadi penyebab kesulitan pembinaan warga gereja di Kewari. Faktor pertama adalah pola hidup masyarakat ditambah dengan kunjungan pendeta yang tidak rutin menjadi faktor pembinaan warga gereja tidak berjalan dengan baik. Itu sebabnya, pembinaan warga gereja melalui peningkatan intensitas perkunjungan perlu ditingkatkan agar hambatan seperti yang terjadi di Kewari dapat diminimalisir. Faktor kedua adalah adanya kesenjangan dalam bahasa antara pendeta dari luar Kewari dengan masyarakat di Kewari. Faktor kedua tersebut tidak dapat lepas dari faktor ketiga yaitu tingkat pendidikan masyarakat Kewari yang masih rendah. Tingkat pendidikan tersebut menyebabkan pola pikir warga gereja di Kewari yang masih harus dibangun dengan baik dan menyebabkan adanya kesenjangan bahasa. Faktor keempat adalah keyakinan masyarakat. Masyarakat Kewari masih kuat memegang keyakinan mereka. Bahkan ada beberapa orang Kristen di Kewari yang masih terlibat dengan upacara $B e$ lian. Secara umum, kesulitan pembinaan warga gereja di Kewari terkait dengan aspek budaya dan kehidupan sosial masyarakat. Dengan kondisi pembinaan warga gereja yang tidak berjalan dengan baik, dipandang perlu bagi denominasi gereja yang memiliki anggota di Kewari menempatkan pendeta yang memahami bahasa setempat, kemudian tinggal tetap di Kewari sehingga masalah yang terkait dengan kebiasaan masyarakat dapat diminimalisir.

BPS. 2011a. Kecamatan Teweh Timur Dalam Angka 2011. Muara Teweh: BPS Kabupaten Barito Utara.

BPS. 2011b. Statistik Daerah Kecamatan Teweh Timur 2011. Muara Teweh: BPS Kabupaten Barito Utara.

Bunsu. 2010. Wawancara Tentang Kebiasan Masyarakat Kewari. (R. Diana, Interviewer) 
Febriyanti, F. 2014. Hambatan Komunikasi Antarbudaya Masyarakat Suku Flores dan Lombok Di Desa Bukit Makmur Kecamatan Kaliorang Kabupaten Kutai Timur". eJournal Ilmu Komunikasi, 2(3): 453-463.

Hanifi, M. L. 2016. Ritual Perang Dalam Kebudayaan Suku Dayak. Sabda , 83-87.

Ihromi, T. 1990. Pokok-Pokok Antropolgi Budaya. Jakarta: Gramedia.

Johnson, D. P. 1986. Teori Sosiologi Klasik dan Moderen. Jakarta: Gramedia.

Kartina. 2015, Juli 15. Wawancara Oleh Penulis. (R. Diana, Interviewer)

Mahin, M. 2009. Kaharingan: Dinamika Agama Dayak di Kalimantan Tengah. Dr. Disertasi, Fakultas Ilmu Sosial dan Ilmu Politik, Departemen Antropologi. Depok: Universitas Indonesia.

Objantoro, E.2017. "Sejarah Dan Pemikiran Kaum Injili Di Tengah-Tengah Perubahan Dan Tantangan Zaman". Evangelikal: Jurnal Teologi Injili dan Pembinaan Warga Jemaat, 1 (2): 129-138.

On, S. 2017. Wawancara Terkait Penerjemahan Alkitab. (R. Diana, Interviewer)
Putri, N. A. 2017. "Kepercayaan (Trust) Masyarakat Suku Dayak Benuaq Pada Pengobatan Tradisional Belian (Studi kasus di Desa Resak, Kutai Barat)". Psikoborneo, 5(3): 620-629.

Riniwati. 2016. "Bentuk Dan Strategi Pembinaan Warga Jemaat". Prosiding Seminar Nasional PAK dan call for papers (pp. 1-13). Ungaran: Sekolah Tinggi Teologi Simpson.

Sidjabat, B. 2014. Pendewasaan Manusia Dewasa. Bandung: Kalam Hidup.

Susanto. 2016. "Strategi Pembinaan Warga Jemaat Dalam Meningkatkan Kehidupan Jemaat (Studi Kasus di GKII Tandang)". Prosiding Semi-nar Nasional PAK I dan call for papers (pp. 14-19). Ungaran: Sekolah Tinggi Teologi Simpson.

Watie, E. D. 2011. "Komunikasi dan Media Sosial". The Messenger, 3(1): 69-75.

Weinstock, J. A. 1996. "Rattan: A Complement to Swidden Agriculture in Borneo". Akademika, 48: 51-61.

Wijaya, P. A., \& Darmawan, I. P.A.2016. Pembekalan Pendekatan Penginjilan Di GKII Gerizim Nusa Dua". Prosiding Seminar Nasional PAK dan call for papers (pp. 52-57). Ungaran: Sekolah Tinggi Teologi Simpson. 